\title{
HELPING BUCHANAN ON HELPING THE REBELS
}

\author{
Daniel Weltman
}

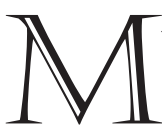

ASSIMO RENZO has recently argued in this journal that Allen Buchanan's account of the ethics of intervention is too permissive. ${ }^{1}$ Renzo claims that a proper understanding of political self-determination shows that it is often impermissible to intervene in order to establish a regime that leads to more self-determination for a group of people if that group was or would be opposed to the intervention. Renzo's argument rests on an analogy between individual self-determination and group self-determination. However, the analogy also points to crucial differences between the two kinds of self-determination. To make his argument work, Renzo must come up with a theory of self-determination that accounts for these differences without vitiating his argument, and it is not clear that this can be accomplished. In response to the differences we may in fact be pushed to adopt an account of self-determination that is more permissive with respect to intervention than even Buchanan's theory.

\section{RENZO'S ARGUMENT AND THE}

\section{ANALOGY BETWEEN INDIVIDUALS AND GROUPS}

Buchanan argues that, for the sake of self-determination, it can make sense to intervene in the affairs of a state, and thus the right to self-determination is not as strong a barrier against intervention as one might have thought. ${ }^{2} \mathrm{He}$ addresses cases in which an oppressive regime is going to crush a democratic revolution or a revolution is going to create an authoritarian government. He argues that, because these are cases in which the state is not or will not be self-determining, it is not a violation of the state's right to self-determination if third parties intervene in order to ensure the creation of a democratic state that would be self-deter-

1 Renzo, "Helping the Rebels"; Buchanan, "The Ethics of Revolution and Its Implications for the Ethics of Intervention"; Buchanan, “Self-Determination, Revolution, and Intervention."

2 His targets include Michael Walzer (Just and Unjust Wars, 84-104), who claims that the only justifiable intervention outside of extreme cases like genocide is one that balances out the intervention of some other party, because anything else would violate self-determination. 
mining. ${ }^{3}$ More controversially, he claims that intervention could be justified in order to overrule a newly elected democratic government if this government is going to eliminate the opportunity for self-determination in the future. Because the right to self-determination is not a right to undercut the ability of others to self-determine, it does not violate a group's self-determination to prevent it from stopping another group (future inhabitants of the country) from exercising self-determination. ${ }^{4} \mathrm{Or}$, it does violate its right, but this is a permissible violation for the sake of others. ${ }^{5}$

Renzo's main response is to point out that Buchanan assumes that we have to look at a group's present exercise of self-determination to decide whether its right to self-determination would be violated by intervention. If we widen our scope to look at the past and at what the group would want right now if it were self-determining, this can give us reason to think that intervention would impermissibly violate the group's self-determination, if in the past it expressed a wish not to be intervened in or if we can reasonably attribute such a desire to the group on the basis of its present values and preferences. ${ }^{6}$ If either of these possibilities suggests that the group did not or does not consent to intervention, then it is an impermissible violation of that group's right to self-determination to intervene.

Renzo aims to make this plausible by giving the example of an individual. Say that you are a pacifist and Renzo takes control of you through hypnosis. If I intervene by killing Renzo and freeing you, even though in the past you told me you would not like me to do this or even though I can infer that, as a pacifist, you would not approve of this, then I have violated rather than protected your self-determination. This is true even though, at the moment, your self-determination is eclipsed because Renzo hypnotized you.

As a story about individuals, let us grant that this works fine. With respect to intervention in groups, though, it is not as clearly compelling, for two reasons: one practical and another theoretical.

First, the practical reason. As Renzo notes, Buchanan is particularly aware of the actual mechanisms by which revolutions and other opportunities for inter-

3 Buchanan, “The Ethics of Revolution and Its Implications for the Ethics of Intervention," 460-61.

4 Buchanan, "The Ethics of Revolution and Its Implications for the Ethics of Intervention," 462 .

5 Buchanan, "The Ethics of Revolution and Its Implications for the Ethics of Intervention," 464 .

6 Renzo, "Helping the Rebels," 231-32. 
vention occur. ${ }^{7}$ Buchanan's concerns are first and foremost about whether the right to political self-determination is an obstacle to intervention in actual cases. In these actual cases, typically it will be very hard to draw conclusions about what the group wanted in the past and what the group would want now. Take for instance Renzo's own example of Cyprus, which signed a treaty in 1960 authorizing other countries to intervene if necessary to reestablish the status quo. ${ }^{8}$ Must we respect this treaty to respect Cyprus's present self-determination? Do the signatories to the treaty (the president and vice president of Cyprus at the time) represent present-day Cyprus (or even past Cyprus)? Matters become even more complicated if we are not dealing with explicit treaties signed by democratically elected leaders. In many of the cases of intervention that we are concerned with, there will be no previous explicit statements about intervention. Even if there are, they will have been made by leaders who were not elected and thus may not have plausibly represented anyone in the past, let alone in the present. Similar issues apply to inferring a group's present desires. How confident can we be that a group actually would or would not desire intervention? The American government famously misjudged how sanguine Iraqis would be at the prospects of an American invasion. Although we might think that this particular judgment was obviously flawed, the general point is that there will often be significant difficulties attached to inferring a group's present preferences absent mechanisms like a fair democratic vote.

Beyond these practical problems lie theoretical difficulties. Groups are different from individuals in many ways. As Renzo alludes to with his reference to Derek Parfit and psychological connectedness, if there is any doubt about the link between your decision in the past and your status in the present, we would not want to give weight to that decision in the past. ${ }^{9}$ For people, there is rarely this kind of doubt, but for groups the doubt is omnipresent. ${ }^{10}$ As Thomas Jefferson pointed out, groups change over time, and this change causes us to wonder about whether a group's past decisions still bind the present:

It is now forty years since the constitution of Virginia was formed.... Within that period, two-thirds of the adults then living are now dead. Have then the remaining third, even if they had the wish, the right to hold

7 Renzo, "Helping the Rebels," 223.

8 Renzo, "Helping the Rebels," 231.

9 Renzo, "Helping the Rebels," 230; Parfit, Reasons and Persons, pt. 3.

10 Of course, if this doubt is omnipresent for people, then Renzo's case is even more tenuous. So, for the sake of the argument, we will assume that the individual case is not problematic. I thank an anonymous reviewer for suggesting I say more about this. 
in obedience to their will, and to laws heretofore made by them, the other two-thirds, who, with themselves, compose the present mass of adults? ${ }^{11}$

This concern for the changing makeup of groups is present in Buchanan's argument, which is focused to a large degree on the importance of using intervention to prevent present people from precluding the self-determination of future people. ${ }^{12}$ Similar concerns apply to using the decisions of a group in the past to determine whether there is a right to intervene in the group now.

The differences between groups and individuals are not limited to the fact that groups change composition over time. Groups are also less clearly delineated than individuals. Individuals, at least in normal cases, have one human body and one mind. Not so for groups. Let us assume that I can easily ascertain which people an individual comprises (there will be just one person). ${ }^{13}$ Figuring out who a group comprises is much less straightforward. Renzo takes it for granted that we know which groups we are talking about and thus whose self-determination is at stake. But we do not. ${ }^{14}$ The Cyprus example is again illustrative. Cyprus has long been divided between Greek Cypriots and Turkish Cypriots. This has occasioned violence and acrimony (including an invasion by Turkey, a partition of the island of Cyprus, and continued Turkish occupation of northern Cyprus), and some very different opinions on what ought to happen in Cyprus. For the purposes of figuring out whose right of self-determination to respect, how many groups do we have? Is there one group of Cypriots, which, according to the principle of majority rule, wants Turkey gone? Are there two groups, one of which wants Turkey to leave and the other that does not mind Turkey's presence? Obviously how we draw the borders for group membership matters quite a bit in terms of figuring out what respect for self-determination entails. Would it respect self-determination if Turkey left, or if Turkey remained?

For these reasons, then, things are not as simple as Renzo presents them. It is straightforward to figure out what I wanted in the past and what I would want now if I could get my way. It is nowhere near as straightforward to do this for groups. So, unless we say more, Buchanan's original arguments withstand Renzo's challenge: for the sake of a group's self-determination, it can make sense to intervene without consent from a group, because the alternatives Renzo raises are not apposite. Unlike the individual case, we cannot straightforwardly

11 Jefferson to Samuel Kercheval, July 12, 1816, 7-8.

12 Buchanan, "The Ethics of Revolution and Its Implications for the Ethics of Intervention," 462, 464.

13 Again, this may be false, but if it is, that is worse for Renzo.

14 For a more complete defense of this point, see Weltman, "Who Is the Self in SelfDetermination?" 
talk about what some group wanted in the past or would want right now in order to figure out whether there is a right to intervene.

\section{WIDENING THE SCOPE OF PERMISSIBLE}

INTERVENTION: A UTILITARIANISM OF RIGHTS

This leaves us with a worry, though. We have just seen how, depending on how we delineate groups, we get very different results in terms of the right to self-determination. If there is one group in Cyprus, Cyprus wants Turkey to leave. If there are two, then one wants Turkey to stay. So, we first need an account of what the relevant groups are before we start to worry about their right to self-determination. Before we can figure out whether intervention violates a group's self-determination, we have to figure out what group or groups we are dealing with. This worry applies to any argument that relies on any sort of right to group self-determination, so it threatens Buchanan as much as it does Renzo.

One solution would be to say that this may be an issue in principle but not in practice. Practically speaking, we know when we are dealing with one group rather than two or more. Unfortunately this seems false in many of the cases in which intervention is a pressing question. Deeply divided societies facing conflicts like revolution are precisely the ones where intervention will be a live topic. Turkey's intervention in Cyprus, for instance, cannot be understood without seeing how Cyprus could coherently have been viewed as a society consisting of at least two groups, rather than one unified society.

Another solution would be to adopt a more specific theory of self-determination than the ones adverted to by Buchanan and Renzo. One option is to say that we only care about self-determination for nations, which are groups that share an encompassing culture. ${ }^{15}$ (This is clearly not what Buchanan has in mind. He argues that his account floats free of this issue and is compatible with whatever account of the group we pick. ${ }^{16}$ ) I cannot adjudicate the entire nationalist versus non-nationalist debate here. What I can say is that if the nationalist account is true and nations are the only sorts of groups with a right to self-determination, it is still not obvious that the past decisions of a nation's self-proclaimed leaders can bind its future members, or that we can easily tell what a nation thinks about some topic if it is not presently able to rule itself. We should worry that if people are not able to vote or otherwise freely express themselves, privileged elites in

15 See Margalit and Raz, "National Self-Determination," 442-47.

16 Buchanan, "Self-Determination, Revolution, and Intervention," 470. Elsewhere, Buchanan rejects nationalistic theories of self-determination. Buchanan, Justice, Legitimacy, and SelfDetermination, 344. 
the nation will claim to speak for the group when in reality they speak for themselves, with the result that elites may reject interventions that the nation more generally would welcome. So we should keep looking.

There are many other options. There is self-determination as:

- a consequence of freedom of association; ${ }^{17}$

- a consequence of the interests that individuals have in being ruled by institutions that reflect their priorities; ${ }^{18}$

- based on the value of individual autonomy; ${ }^{19}$

- based on individual interests in establishing and revising laws and public norms; $;^{20}$

- based on the value of collective autonomy; ${ }^{21}$

- ownership of state institutions due to past contributions. ${ }^{22}$

Renzo, like Buchanan, does not commit to any particular theory. ${ }^{23}$ Each of these theories has a different way of picking out the relevant groups and thus telling us whether, say, Cyprus is one "self" or two "selves" when it comes to self-determination, at least in principle. At the very least, Renzo needs to provide an account that is convincing in light of the practical concerns Buchanan has in mind, because in messy cases like Cyprus we cannot take for granted that we know how many "selves" we are dealing with or how stable over time those "selves" are. There are, moreover, reasons to worry that any account of the "self" can provide a good theoretical answer to questions of potentially divided selves, or a good practical answer in the messy cases of potential intervention. ${ }^{24}$

I would thus like to suggest a solution to this question that Buchanan rejects, one he calls a "utilitarianism of rights," according to which we should aim to resolve these questions by figuring out what would best promote self-determination for the most people (or best promote the average amount of self-determination among all people, or some other consequentialist sort of aggregation

17 Altman and Wellman, A Liberal Theory of International Justice.

18 Stilz, “The Value of Self-Determination."

19 Nagel, "The Problem of Global Justice”; Banai, "Political Self-Determination and Global Egalitarianism."

20 Levitov, "Human Rights, Self-Determination, and External Legitimacy."

21 Moore, A Political Theory of Territory, 65.

22 Pevnick, Immigration and the Constraints of Justice.

23 Renzo suggests his theory is compatible at least with Moore and Stilz. He also cites three unpublished manuscripts that describe his own theory. Renzo, "Helping the Rebels," 227, 232n28, 234n34.

24 I argue for this claim in Weltman, "Who Is the Self in Self-Determination?" and "Against Innovative Accounts of Self-Determination.” 
scheme that works on the level of individuals), rather than being precious about making sure each particular group has its own right to self-determination. ${ }^{25}$ Are there one or two groups in Cyprus? Pick the cleavage that would let the most people rule themselves rather than be ruled by others, or that would lead to the greatest amount of self-determination for any given individual that is compatible with at least that amount for everyone else, or some other individual-centric calculation. ${ }^{26}$ One main worry with this utilitarianism of rights is that some groups would be thrown under the bus for the sake of other individuals in other groups. But there is no possibility of a world with perfect borders, especially if we are aiming to be practical and resolve the hardest cases, like the ones relating to intervention. There are always going to be clashes of self-determination with some winners and some losers. A utilitarianism of rights just aims to make sure we pick the losers by minimizing the number of people who lose out on self-determination (or the number of people with the minimal acceptable level of self-determination, or something like this), rather than via some other means that prioritize the choices of groups rather than outcomes for individuals.

We can picture examples where this gives us absurd results, like large State $A$ intervening in small State $B$ for the sake of promoting State A's self-determination, leaving State $B$ less self-determining. This is a possibility we open ourselves up to with any sort of utilitarian approach. In actual cases, though, we need not worry about these possibilities for the same reason a utilitarian of personal autonomy rights potentially does not need to worry about slavery. The utilitarian of personal autonomy rights argues that although, in principle, subjugating some might be a way of maximizing personal autonomy, in practice slavery is such a huge violation of autonomy that it is practically impossible to justify it with gains in personal autonomy for others. It is not important whether this argument vindicates utilitarianism of personal autonomy. ${ }^{27}$ What is important is that the analogous claim is true with respect to political self-determination. This is because even in the rare cases in which the empirical claim is false in the political sphere, it is much less objectionable to compromise the autonomy of a group for the sake of other groups. As noted above, groups of people will always exist that are not able to be self-determining unless we compromise on some other group's self-determination, which means that we are going to have to

25 Buchanan, “The Ethics of Revolution and Its Implications for the Ethics of Intervention," 466. Recall that Buchanan is fine with weighing rights violations against each other-he just does not want to collapse entirely into a utilitarianism of rights.

This would likely entail the conclusion that there are two groups in Cyprus, but I do not want to commit to any particular solution to this actual case.

I think it does not. I thank an anonymous reviewer for suggesting that I address this worry. 
compromise (whereas one might think we should never compromise in the case of individuals). In other words, political self-determination is not an inviolable right, at least for practical purposes, and if it is not inviolable, we might as well be utilitarians (of a sort).

So, we have vindicated Buchanan, albeit via a utilitarianism of rights that he wished to avoid. But we have chosen a utilitarianism of rights for groups in part because we are avoiding utilitarianism for individuals. For each individual person, what matters is that we aim to secure their belonging to a group in which they have self-determination, even if this requires seeing two groups where we might have seen one, or one where we before saw two. Exactly the reason utilitarianism is perhaps a bad fit for people - the fact that each person is a distinct, separate individual —is why utilitarianism is a fine fit for groups that exist for the sake of people. It is the people we care about, not the groups, and if some arrangement of groups would better serve people, we should endorse that arrangement. As Laura Valentini puts it, "individual human beings' status as equal and ultimate units of moral concern" rules out using a collective agent, rather than individual agents, as the locus of concern: "the moral standing of a collective is explained by, and therefore conditional on, the collective's serving the legitimate interests of individuals." ${ }^{28}$ We respect the rights of collectives only insofar as those collectives are good for individuals. This is incompatible with an inviolable group right to self-determination, but so much the worse for an inviolable group right to self-determination.

There is even a case to be made for pushing the logic of self-determination further. Charles Beitz argues that "claims of a right to self-determination, when pressed by or on behalf of residents of a colony, are properly understood as assertions that the granting of independence would help reduce social injustice in the colony," and this point is not limited just to colonies. ${ }^{29}$ "Self-determination," he says, "is a means to the end of social justice," not a fundamental right in and of itself..$^{30}$ Perhaps justice, broadly speaking, is what ultimately matters, and we ought to compromise self-determination for its sake. ${ }^{31}$ This would move even further from Buchanan's original goal, and leave use closer to a more traditional cosmopolitan, justice-centric view. This rejection of self-determination is "implicit in many cosmopolitan theories of global justice," according to Lea Ypi. ${ }^{32}$

Valentini, "On the Distinctive Procedural Wrong of Colonialism," 324.

Beitz, Political Theory and International Relations, 104.

Beitz, Political Theory and International Relations, 104.

31 I argue this in Weltman, "There Is Nothing Per Se Wrong with Colonialism."

32 Ypi, “Territorial Rights and Exclusion," 251. 
Buchanan will see this as a downside, but for the reasons adduced above it may instead be a good result.

Whether we go this far, stop at a utilitarianism of rights, or even stop at acknowledging the differences between individuals and groups, the central point remains. Unless we can find some way around the worries about group agency raised above, it is not clear that Buchanan is wrong to posit a wider scope for intervention than Renzo supports. ${ }^{33}$

\author{
Ashoka University \\ danny.weltman@ashoka.edu.in
}

\title{
REFERENCES
}

Altman, Andrew, and Christopher Heath Wellman. A Liberal Theory of International Justice. New York: Oxford University Press, 2009.

Banai, Ayelet. "Political Self-Determination and Global Egalitarianism: Towards an Intermediate Position." Social Theory and Practice 39, no. 1 (January 2013): $46-69$.

Beitz, Charles. Political Theory and International Relations. Princeton: Princeton University Press, 1979.

Buchanan, Allen. "The Ethics of Revolution and Its Implications for the Ethics of Intervention." Philosophy and Public Affairs 41, no. 4 (Fall 2013): 291-323.

- Justice, Legitimacy, and Self-Determination: Moral Foundations for International Law. Oxford: Oxford University Press, 2004.

- "Self-Determination, Revolution, and Intervention." Ethics 126, no. 2 (January 2016): 447-73.

Jefferson, Thomas. Thomas Jefferson to Samuel Kercheval, July 12, 1816. In The Thomas Jefferson Papers at the Library of Congress: Series 1: General Correspondence.https://www.loc.gov/resource/mtj1.049_0255_0262.

Levitov, Alex. "Human Rights, Self-Determination, and External Legitimacy." Politics, Philosophy and Economics 14, no. 3 (August 2015): 291-315.

Margalit, Avishai, and Joseph Raz. "National Self-Determination." Journal of Philosophy 87, no. 9 (September 1990): 439-61.

Moore, Margaret. A Political Theory of Territory. New York: Oxford University Press, 2015.

Nagel, Thomas. "The Problem of Global Justice." Philosophy and Public Affairs 33, no. 2 (March 2005): 113-47.

33 Thanks to an anonymous reviewer for this journal for their very helpful comments. 
Parfit, Derek. Reasons and Persons. Oxford: Clarendon Press, 1984.

Pevnick, Ryan. Immigration and the Constraints of Justice: Between Open Borders and Sovereignty. Cambridge: Cambridge University Press, 2011.

Renzo, Massimo. "Helping the Rebels." Journal of Ethics and Social Philosophy 13, no. 3 (July 2018): 222-39.

Stilz, Anna. "The Value of Self-Determination." In Oxford Studies in Political Philosophy, vol. 2, edited by David Sobel, Peter Vallentyne, and Steven Wall, 98-127. New York: Oxford University Press, 2016.

Walzer, Michael. Just and Unjust Wars. New York: Basic Books, 1977.

Weltman, Daniel. "Against Innovative Accounts of Self-Determination." Unpublished manuscript.

_ . "There Is Nothing Per Se Wrong with Colonialism." Unpublished manuscript.

"Who Is the Self in Self-Determination?" Unpublished manuscript.

Valentini, Laura. "On the Distinctive Procedural Wrong of Colonialism." Philosophy and Public Affairs 43, no. 4 (Fall 2015): 312-31.

Ypi, Lea. “Territorial Rights and Exclusion.” Philosophy Compass 8, no. 3 (March 2013): 241-53. 